\title{
Visual Perception of Elliptic movements in 7- to-11- year-old children : Influence of Motor Rules
}

Christel Bidet-Ildei, David Méary and Jean-Pierre Orliaguet

\section{Q OpenEdition \\ 1 Journals}

Electronic version

URL: http://journals.openedition.org/cpl/1071

DOI: $10.4000 / \mathrm{cpl} .1071$

ISSN: $1379-6100$

Publisher

Centre PsyCLÉ

\section{Electronic reference}

Christel Bidet-Ildei, David Méary and Jean-Pierre Orliaguet, «Visual Perception of Elliptic movements in 7- to-11-year-old children : Influence of Motor Rules », Current psychology letters [Online], 19, Vol. 2, 2006 | 2006, Online since 14 December 2006, connection on 07 September 2020. URL : http:// journals.openedition.org/cpl/1071; DOI : https://doi.org/10.4000/cpl.1071

This text was automatically generated on 7 September 2020

(c) All rights reserved 


\title{
Visual Perception of Elliptic movements in 7- to-11-year-old children : Influence of Motor Rules
}

\author{
Christel Bidet-Ildei, David Méary and Jean-Pierre Orliaguet
}

Received January 3, 2006

Revised September 27, 2006

Accepted October 5, 2006

On line December 14, 2006

INTRODUCTION

The human visual system is extremely sensitive to human motion. In the past, several studies showed that, even when movement is represented by a simplified point-light display, observers can discriminate human body movements from moving objects (Bingham, Schmidt, \& Rosenblum, 1995). They identify actions such as walking or dancing (Johansson, 1973, 1975), the gender and the identity of a person (Cutting \& Kozlowski, 1977; Kozlowski \& Cutting, 1977) and even the properties of handled objects such as the weight of a lifted object (Runeson \& Frykholm, 1981, 1983). Other results showed that when subjects have to visually evaluate the velocity of human movements (i.e., pointing movement, handwriting, drawing an ellipse) they prefer those that conformed to motor laws (Meary, Chary, Palluel-Germain, \& Orliaguet, 2005; Viviani \& Stucchi, 1989). For example when a subject is asked to adjust the velocity of a reaching movement, a writing movement or an elliptic movement, he/she tends to choose durations of movement which are respectively in line with the Fitts' Law, the isochrony principle and the two-third power law. To explain this high sensibility to human movement, it has been suggested that visual identification of human movement could be not only based on visual experience but also on motor experience (i.e., Jeannerod, 2001; Jeannerod \& Frak, 1999). In others words the recognition of human movements would be the result of motor-perceptual interactions. Several results are in accord with this view. Observers better recognise point-light displays representing their own movement than movements of their friends (Beardsworth \& Buckner, 1981; Loula, 
Prasad, Harber, \& Shiffrar, 2005). Patients with motor deficits often have difficulties to recognise human movements as this is the case for dysgraphic (Chary et al., 2004) and apraxic (Heilman, Rothi, \& Valenstein, 1982) patients. Finally, neuroimaging studies show that both observation and execution of movements activate common brain regions (Hari et al., 1998; Peuskens, Vanrie, Verfaillie, \& Orban, 2005; Saygin, Wilson, Hagler, Bates, \& Sereno, 2004).

Some developmental studies also indicate that the motor competence of the observer could be involved, at least in part, in the visual perception of human movements. For example, children with articulatory disorders (i.e., $d / b$ confusion) have more difficulties in lips reading than children without such motor difficulties (Desjardins, Rogers, \& Werker, 1997). In the same way, reading deficits is often associated with motor disorders (Felmingham \& Jakobson, 1995). Finally, an experiment carried out by Louis-Dam, Kandel and Orliaguet (2000) showed that in children the ability to visually anticipate the forthcoming movement in a motor sequence is directly influenced by their level of motor competence.

In this theoretical context, the aim of the present research is to bring additional evidence that, in children, visual perception of human movement is influenced by motor rules. To this end, 7 to 11 year-old children were asked to evaluate and to adjust the velocity of a dot depicting an elliptic movement. In motor production, Viviani and Schneider (1991) showed that from 7 years, the duration of elliptic movements conforms to the isochrony principle: the duration of the movement tended to be constant irrespective of the perimeter of the ellipse. If, as showed by former studies that visual perception of human movement tends to conform to motor rules, the visual evaluation of time movement will also tend to conform to the isochrony principle from 7 years of age.

\section{METHODParticipants}

Forty-five children participated in the experiment. They were divided into 3 age groups of 15 children each: 7 years (mean age 6 years 11 months), 9 years (mean age 8 years 9 months) and 11 years (mean age 10 years 9 months). A group of 15 adults, students at the university, was used as control. All subjects were right-handed and had normal or corrected to normal vision.

Stimuli

The visual stimuli consisted of 6 elliptic movements. The perimeter of the ellipse was respectively $2.94,5.25,9.36,16.69,29.74$ or $53 \mathrm{~cm}$ long. The semi axis ratio b/a (0.425) and the eccentricity of the ellipse $\Sigma(0.9)$ were constant whatever the perimeter of the ellipse (see figure 1). The major semi axis of the ellipse a was rotated by 45 degrees counter-clockwise. A software permitted to modify the trajectory perimeter $(\mathrm{Pe})$ or the movement period (P). For all period values, the velocity profile of the movement respected the two-third power law (covariation velocity-curvature) observed in the production of movement (Lacquaniti, Terzuolo, \& Viviani, 1983). 


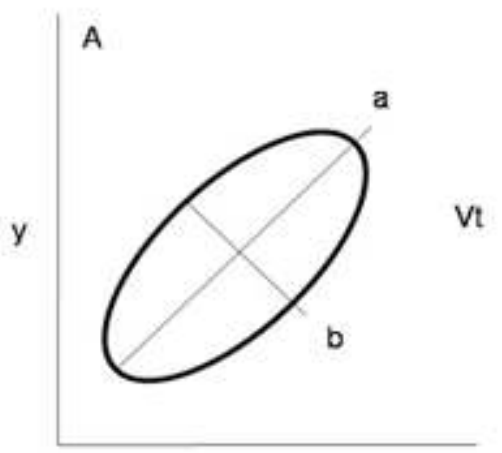

$x$
B

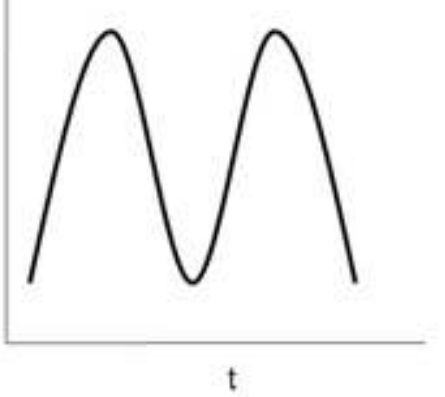

Figure 2: Kinematic characteristics of the stimulus. A) Form of the elliptic trajectory. B) Velocity profile for one period (one cycle) with Vt corresponding to the tangential velocity and $\mathrm{t}$ to the movement time.

Procedure

Participants seated at a distance of $50 \mathrm{~cm}$ from a computer screen (17', resolution $1024^{*} 768$ pixels, sampling rate $85 \mathrm{~Hz}$ ) in a dimly illuminated room (see figure 2). Each trial consisted in the presentation of a black spot $(\varnothing=0.4 \mathrm{~cm})$ depicting an elliptic movement on a white background area $\left(22^{*} 22 \mathrm{~cm}\right)$. Participants were asked to adjust the period of movement (that is to find their "preferred velocity") by pressing the arrows ( $\leftarrow$ or $\rightarrow$ ) of the keyboard. The adjustments allowed increasing or decreasing of the duration of the period by step of $25 \mathrm{~ms}$.

The experiment was run in a single session including 6 blocks of trials. Each block comprised 6 trials corresponding to each perimeter of the ellipse. Therefore each subject performed 36 trials. The order of presentation of blocks and trials, and the initial period value of each trial $(\mathrm{Pi})$ were randomized. Short periods of rest separated each block of trial. 


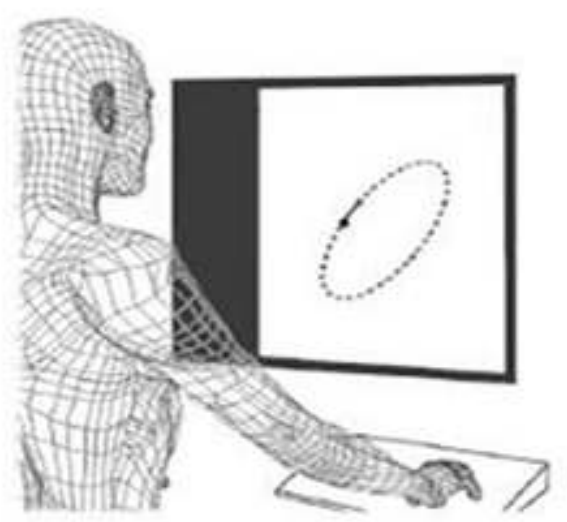

Figure 2: Experimental set up. Subject was in front of a screen. A dot depicted an elliptic trajectory. The task consisted in adjusting the velocity by using the arrows of the keyboard.

Data analysis

The results were analysed by using the same formalisation and the same procedure than those used in Viviani \& Schneider's experiment (1991). The relation between the perimeter of the ellipse $(\mathrm{Pe})$ and the final period $(\mathrm{Pf})$ chosen by the participants was formalised by the power function $\mathrm{Pf}=\mathrm{P0}{ }^{*} \mathrm{Pe}^{\gamma}$ where $\gamma$ represents the exponent of the function and P0 a baseline period which depends of each subject (see figure 3). Then, we evaluated for each subject the coherence of the results, the degree of isochrony and the movement speed by measuring the correlation coefficient $r$ ), the exponent $\gamma$ ) and the baseline period ( $\mathrm{PO}$ ) according to age.

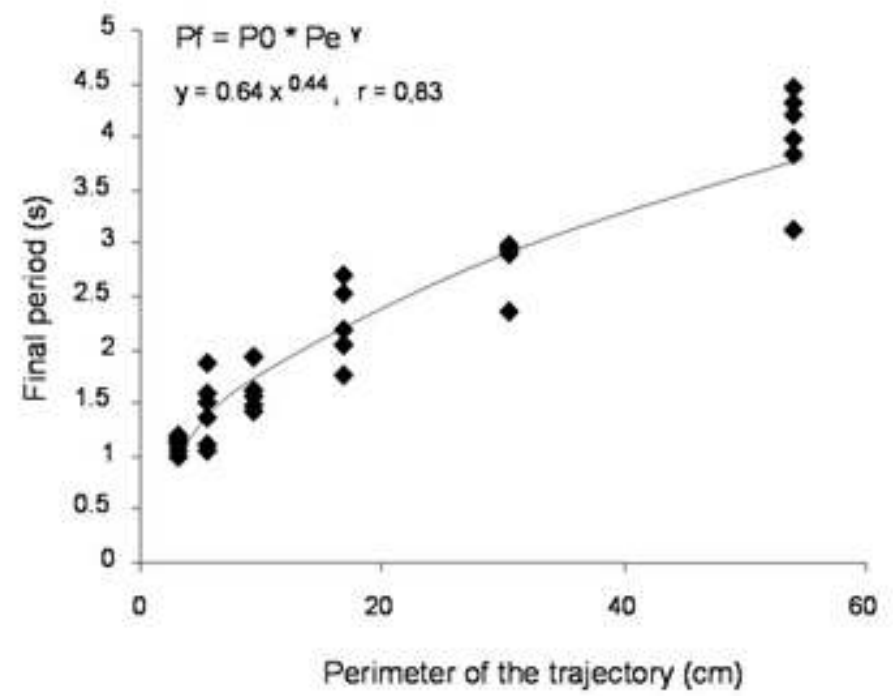

Figure 3: Example of the power approximation $\mathrm{Pf}=\mathrm{P} 0 * \mathrm{Pe}^{\gamma}$ for one participant chosen randomly in the adult group. 


\section{RESULTS}

The mean of the correlation coefficient, of the exponent, and of the baseline period were calculated and statistically evaluated with an ANOVA with age as between factor.

Because the correlation coefficients and the baseline period (P0) did not follow a normal distribution, data has been transformed. For the coefficients of correlation we used the Fisher hyperbolic tangent transform (Kendall \& Stuart, 1979) and the baseline period was analysed by using the logarithm of P0. Results obtained in children and in adults were analysed separately.

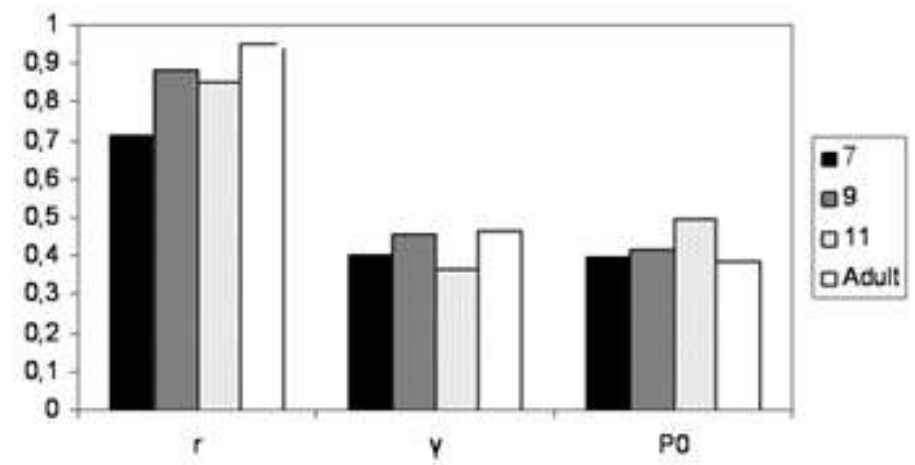

Figure 4: Mean of the correlation coefficients ( $r$ ), of the exponents $\gamma$ ) and the baseline periods (P0) as a function of age.

Correlation coefficient $(\mathrm{r})$ : the statistical analysis revealed a significant effect of age [F $(2,42)=6.09, p<0.01]$. We observed an increase of $r$ value between $7(0.71)$ and 9 years (0.88), a stabilisation between 9 and 11 years (0.85) and again an increase between 11 year-old children and adults $(0.95)[t(28)=3.67, p<0.01]$. This result indicates that the within variability is higher at 7 years and tends to decrease with age. However, it should be noted that whatever the age, the values of the coefficient correlations are very high. This result shows that the link between the final period and the perimeter of the ellipse is well approximated by the power function.

Exponent $\gamma$ ): there was no effect of age $[F(2,42)=1.54, p=0.22]$. It is noteworthy that the mean value of $\gamma(0.41 \pm 0.14)$ is not different from the value $(0.44)$ obtained by Viviani and Schneider (1991) in the motor task $[t(44)=1.61, p=0.11]$. In addition, we did not observe any significant difference between children $(0.41 \pm 0.14)$ and adults $(0.46 \pm 0.19)[t(58)=0.98, p=0.33]$.

Baseline period (P0): age has no effect on the performances $[F(2,42)=0.40, p=0.67]$. Whatever the age, the mean baseline period was $0.43 \mathrm{~s}$ and no significant difference was observed between children $(0.42 \pm 0.29)$ and adults $(0.37 \pm 0.20)[t(58)=0.73, p=$ $0.46]$.

\section{DISCUSSION}

The purpose of this experiment was to know if the visual perception of human movements was influenced by the rules of motor production. Our results showed a very 
high similarity between the performances observed in the visual perception of elliptic movements and those obtained by Viviani \& Schneider in the motor production of ellipses (1991). Indeed the exponents of the power function which defines the relation between perimeter and time movement (the final period chosen by the subject) are not different in the perceptive (0.41) and motor tasks (0.44). Therefore these findings indicate that in children, from 7 year-old, the isochrony principle is observable both in production and in perception. Though the perimeter was multiplied by 18 (2.53 to 53 $\mathrm{cm}$ ), the final period chosen by the participant was only multiplied by 3 (930 to 2606 ms). Therefore, these findings demonstrate that a similar principle determines motor and perceptual performances and suggest that the perceptual abilities of children may depend on their level of motor development.

Such similarities between perceptual and motor behaviours may be interpreted within the motor simulation theory (Jeannerod, 2001). According to this theory, the motor system is considered at a covert stage as a simulation system that is activated in selfintended action and also in the recognition of others' action. At this covert stage, action is not executed but the way to reach the goal and the consequences of the action on both the organism and the external world are simulated. Therefore it can be hypothesised that when perceiving a movement, children based their decision on an internalized simulation of the ellipse movement that leads to prefer stimuli that share common kinematic properties with their own motor productions, that is those which conform to the isochrony principle. This assumption is in accordance with clinical observations showing the role of motor competence in the visual perception of human movement (i.e., Chary et al., 2004) and with neuroimaging studies showing the activation of neuronal motor structures during the visual perception of human movements (Chaminade, Meary, Orliaguet, \& Decety, 2001; Decety et al., 1997; Hari et al., 1998; Nishitani \& Hari, 2000; Rizzolatti et al., 1996).

Though, the numerous evidences for a connection between perception and action, few authors consider that the visual perception of dynamic events could be determined by general invariants which have emerged from evolution of species and which would be present from the beginning of the development, that is long before the emergence of motor competences (Shepard \& Zare, 1983; Vallortigara, Regolin, \& Marconato, 2005). This hypothesis is supported by some results obtained in infants and in patients with impaired motor functions. Fox and McDaniel (1982) demonstrated that 8 week-old infants exhibit a preference for a point-light walker over the same configuration inverted 180 degrees. Moreover it has been showed that by 3-5 months of age, infants discriminate a point-light walker from displays with perturbed local rigidity (Bertenthal, Proffitt, \& Kramer, 1987) or with scrambled spatial relations between the dots (Bertenthal, Proffitt, \& Cutting, 1984). In addition Pavlova and her colleagues (2003) have shown that adolescents with congenitally impaired locomotion can exhibit high sensitivity to a point-light walker. Therefore these results show that motor competences are not necessary to perceive and recognize human movements.

Animal studies point to a similar conclusion by suggesting that the perception of biological movement could be an intrinsic capacity of the vertebrate visual system. For example, Vallortigara et al (2005) reported that chicks, hatched and reared in darkness, exhibit a preference to biological movements from the first presentation of the stimuli after birth. They tend to prefer the biological movement of a hen than a rigid or random motion. It is noteworthy that a similar behaviour is observed when the stimuli 
represent the movement of a cat. This latter result suggests that the preference for biological motion in newborn chick is not species-specific and therefore does not depend on motor ability.

Taken together these results suggest that the isochrony principle observed in visual perception could be explained either by an activation of the motor system or by a genetic predisposition. Our experiment carried out in 7-to-11-year-old children does not permit to conclude, though it seems hardly plausible that all the motor rules are available at birth. It however demonstrates that in children visual perception of an elliptic movement is directly influenced by some intrinsic properties of the motor system, i.e., the isochrony principle.

\section{BIBLIOGRAPHY}

Beardsworth, T., \& Buckner, T. (1981). The ability to recognize oneself from a video recording of one's movements without seeing one's body. Bulletin of the Psychonomic Society, 8, 19-22.

Bertenthal, B. I., Proffitt, D. R., \& Cutting, J. E. (1984). Infant sensitivity to figural coherence in biomechanical motions. Journal of Experimental Child Psychology, 37(2), 213-230.

Bertenthal, B. I., Proffitt, D. R., \& Kramer, S. J. (1987). Perception of biomechanical motions by infants: implementation of various processing constraints. Journal of Experimental Psychology: Human Perception and Performance, 13(4), 577-585.

Bingham, G. P., Schmidt, R. C., \& Rosenblum, L. D. (1995). Dynamics and the orientation of kinematic forms in visual event recognition. Journal of Experimental Psychology: Human Perception and Performance, 21(6), 1473-1493.

Chaminade, T., Meary, D., Orliaguet, J. P., \& Decety, J. (2001). Is perceptual anticipation a motor simulation? A PET study. Neuroreport, 12(17), 3669-3674.

Chary, C., Meary, D., Orliaguet, J. P., David, D., Moreaud, O., \& Kandel, S. (2004). Influence of motor disorders on the visual perception of human movements in a case of peripheral dysgraphia. Neurocase, 10(3), 223-232.

Cutting, J. E., \& Kozlowski, L. (1977). Recognizing friends by their walk: Gait perception without falimiarity cues. Bulletin of the Psychonomic Society, 9, 353-356.

Decety, J., Grezes, J., Costes, N., Perani, D., Jeannerod, M., Procyk, E., et al. (1997). Brain activity during observation of actions. Influence of action content and subject's strategy. Brain, 120(Pt 10), 1763-1777.

Desjardins, R. N., Rogers, J., \& Werker, J. F. (1997). An exploration of why preschoolers perform differently than do adults in audiovisual speech perception tasks. Journal of Experimental Child Psychology, 66(1), 85-110.

Felmingham, K. L., \& Jakobson, L. S. (1995). Visual and visuomotor performance in dyslexic children. Experimental Brain Research, 106(3), 467-474. 
Fox, R., \& McDaniel, C. (1982). The perception of biological motion by human infants. Science, 218(4571), 486-487.

Hari, R., Forss, N., Avikainen, S., Kirveskari, E., Salenius, S., \& Rizzolatti, G. (1998). Activation of human primary motor cortex during action observation: a neuromagnetic study. Proceedings of the National Academy of Sciences of the United States of America, 95(25), 15061-15065.

Heilman, K. M., Rothi, L. J., \& Valenstein, E. (1982). Two forms of ideomotor apraxia. Neurology, 32(4), 342-346.

Jeannerod, M. (2001). Neural simulation of action: a unifying mechanism for motor cognition. Neuroimage, 14(1 Pt 2), S103-109.

Jeannerod, M., \& Frak, V. (1999). Mental imaging of motor activity in humans. Current Opinion in Neurobiology, 9(6), 735-739.

Johansson, G. (1973). Visual perception of biological motion and a model for its analysis. Perception \& Psychophysics, 14, 201-211.

Johansson, G. (1975). Visual motion perception. Scientific American, 232(6), 76-88.

Kendall, M., \& Stuart, A. (1979). The advanced theory of statistics (Vol. 2). London: Charles Griffin. Kozlowski, L., \& Cutting, J. E. (1977). Recognizing the sex of a walker from dynamic point-light displays. Perception \& Psychophysics, 21, 575-580.

Lacquaniti, F., Terzuolo, C., \& Viviani, P. (1983). The law relating the kinematic and figural aspects of drawing movements. Acta Psychologica (Amst), 54(1-3), 115-130.

Louis-Dam, A., Kandel, S., \& Orliaguet, J.-P. (2000). Anticipation motrice et anticipation perceptive. Psychologie Française, 45, 333-342.

Loula, F., Prasad, S., Harber, K., \& Shiffrar, M. (2005). Recognizing people from their movement. Journal of Experimental Psychology: Human Perception and Performance, 31(1), 210-220.

Meary, D., Chary, C., Palluel-Germain, R., \& Orliaguet, J. P. (2005). Visual perception of writing and pointing movements. Perception, 34(9), 1061-1067.

Nishitani, N., \& Hari, R. (2000). Temporal dynamics of cortical representation for action. Proceedings of the National Academy of Sciences of the United States of America, 97(2), 913-918.

Pavlova, M., Staudt, M., Sokolov, A., Birbaumer, N., \& Krageloh-Mann, I. (2003). Perception and production of biological movement in patients with early periventricular brain lesions. Brain, 126(Pt 3), 692-701.

Peuskens, H., Vanrie, J., Verfaillie, K., \& Orban, G. A. (2005). Specificity of regions processing biological motion. European Journal of Neuroscience, 21(10), 2864-2875.

Rizzolatti, G., Fadiga, L., Matelli, M., Bettinardi, V., Paulesu, E., Perani, D., et al. (1996). Localization of grasp representations in humans by PET: 1. Observation versus execution. Experimental Brain Research, 111(2), 246-252.

Runeson, S., \& Frykholm, G. (1981). Visual perception of lifted weight. Journal of Experimental Psychology: Human Perception and Performance, 7(4), 733-740.

Runeson, S., \& Frykholm, G. (1983). Kinematic specification of dynamics as an informational basis for person and action perception: Expectation, gender recognition, and deceptive intention. Journal of Experimental Psychology: General, 112, 585-615.

Saygin, A. P., Wilson, S. M., Hagler, D. J., Jr., Bates, E., \& Sereno, M. I. (2004). Point-light biological motion perception activates human premotor cortex. Journal of Neuroscience, 24(27), 6181-6188. 
Shepard, R. N., \& Zare, S. L. (1983). Path-guided apparent motion. Science, 220(4597), 632-634.

Vallortigara, G., Regolin, L., \& Marconato, F. (2005). Visually inexperienced chicks exhibit spontaneous preference for biological motion patterns. PLoS Biology, 3(7), e208.

Viviani, P., \& Schneider, R. (1991). A developmental study of the relationship between geometry and kinematics in drawing movements. Journal of Experimental Psychology: Human Perception and Performance, 17(1), 198-218.

Viviani, P., \& Stucchi, N. (1989). The effect of movement velocity on form perception: geometric illusions in dynamic displays. Perception \& Psychophysics, 46(3), 266-274.

\section{ABSTRACTS}

The aim of the present study is to analyse the visual perception of human movements in children. We evaluated whether the isochrony motor principle (that is the tendency to maintain constant the duration of movement across change of movement amplitude) is at work in a perceptive task. Children, aged 7 to 11 years, had to adjust the velocity (the period) of a dot depicting an elliptic motion. The size of the ellipse varied from 2.94 to $53 \mathrm{~cm}$. Results showed that the relation between the chosen period and the size of the ellipse corresponded to that observed in motor production (Viviani \& Schneider, 1991) : From 7-year-old perceptual adjustments were in agreement with the isochrony principle. The results are discussed in terms of motorperception relationships.

Cette recherche porte sur la perception visuelle des mouvements humains chez l'enfant. Le but est de vérifier si le principe d'isochronie (tendance à maintenir le temps de mouvement constant quelle que soit son amplitude) que l'on observe sur le plan moteur est également présent sur le plan perceptif. On présentait sur un écran un point décrivant une trajectoire elliptique. La taille de l'ellipse variait de 2.94 à $53 \mathrm{~cm}$. Des enfants âgés de 7 à 11 ans devaient ajuster selon leur préférence la vitesse (période) du mouvement. Les résultats montrent que la relation ente la période choisie et la taille de l'ellipse correspond à celle observée lors de la réalisation du mouvement (Viviani et Schneider, 1991) : dès 7 ans les ajustements perceptifs sont conformes au principe d'isochronie. Ces résultats permettent de discuter les liens motricité-perception.

\section{INDEX}

Keywords: human movement, isochrony principle, motor-perceptual interactions, Visual perception

\section{AUTHORS}

\section{CHRISTEL BIDET-ILDEI}

Laboratory of Psychology and Neurocognition CNRS, UMR 5105

\section{DAVID MÉARY}

Université Pierre Mendès France, 38040 Grenoble Cedex 9, France. 
JEAN-PIERRE ORLIAGUET

christel.ildei@upmf-grenoble.fr 